\title{
Thinking beyond the contract: A journey to collaborative community social work
}

\section{Stefanie Döbl and Amy Ross}

Stefanie Döbl is a registered social worker based at Newtown Union Health Service, a primary health care practice in Wellington. Having practised social work both in Aotearoa New Zealand and overseas for 10 years, she feels honoured in having the opportunity to work closely with people from Wellington's diverse communities. Stefanie is also currently studying towards a Master of Health Sciences.

Amy Ross is a community social worker working for St Vincent de Paul in Newtown, Wellington. With bachelor and masters degrees in social work from Massey university Amy has 14 years' experience in the NGO sector. Passionate about social work and social workers Amy is an outspoken advocate of social justice and the connection that social work can and should have to challenging injustice in whatever guise it may appear.

\section{Abstract}

Social workers from two different Wellington-based community service providers, Newtown Union Health Service (NUHS) and St Vincent de Paul (SVDP) Wellington Area discuss their organisations and how they worked together to build an award-winning ${ }^{1}$ practice model in their community. Their reflection on their work raises important questions regarding our responsibilities and options to meet client needs in a heavily contracted funding environment and presents the learnings and challenges of their collaboration.

\section{Introduction}

Funding matters are of great importance for social services in general and are often a daily reality to be negotiated. This is particularly true during difficult economic times where funding becomes highly restricted. For us reflecting on conversations with colleagues in the community in the last few months, concerns over funding continue to be significant. This trend is also visible in social work literature, both nationally and internationally (Aimers \& Walker, 2008; Carey, 2008; Ferguson, 2008; Hibbs, 2005). It is not solely the issue of 'not enough' money, though that is certainly the case for many agencies, but also the issue of how many of the funding contracts that agencies have access to heavily regulate and control service provision.

Funding contracts are normally tied to specific conditions such as demographics and/ or catchment areas. On the one hand, detailed requirements may enhance clarity, set useful boundaries and increase evaluation abilities (Hughes \& Wearing, 2007). On the other hand,

Winner 2012 Capital and Coast District Health Board Commitment to Quality Improvement Award. 
it is widely recognised that social work does not fit in clear-cut boxes with easily defined and measured outcomes due to the immense variation in needs and levels of complexity present in different individuals and communities (Harms \& Connolly, 2009). Hence the regulation that accompanies many funding contracts can actually mean that some people or communities can be left behind.

So, what can social workers do if they have identified that people of their wider community are not able to get the support they may seek because they do not fit service requirements due to specific funding criteria? This is the question we both faced and hence address in this personalised article from two different perspectives.

This article introduces the reader to the community in which we are operating and the two organisations we work for. The introduction is followed by an outline of each of our experiences in four stages: the beginning, the growth, today and the future. We reflect on the learnings and challenges we have experienced before finishing off with joint conclusions and recommendations.

\section{Our community}

The community that we are working from in the context of this article is Newtown, Wellington. Our clients also come from further afield than this, yet the core base and largest visible presence for both our agencies is within this community.

Newtown is a suburb of Wellington bordered by Berhampore, Kilbirnie and the central city. Newtown is a culturally rich community with higher than average percentages of Asian, Pacific Island and Middle Eastern/Latin American / African peoples (Statistics New Zealand, 2006). Newtown also is a community where $45.1 \%$ of people over 15 earn $\$ 20,000$ or less, meaning it faces greater socio-economic hardship than Wellington as a whole (Statistics New Zealand, 2006).

Newtown is also the home of many social service agencies, many of whom play a valuable part in what is a diverse and expansive community.

\section{Our agencies}

\section{Newtown Union Health Service}

NUHS is a community-owned and not-for-profit organisation which was founded in 1987. Its aim is to deliver affordable, acceptable, appropriate and accessible primary health care services. Hence, a multi-disciplinary team approach is utilised. As part of providing holistic primary health care services, NUHS has employed a social worker since its establishment. Today, the social work position is full-time and contracted to work with women and children. The social work role has a generalist approach which focuses on social work assessment, short- to medium-term social work interventions and advocacy.

There are about 6,600 patients currently enrolled (Newtown Union Health Service, 2011). The majority experience struggles in addressing their basic health and social needs. Their (mental) health is often extensively impacted by the wider social determinants of health (such as overcrowding, inability to afford healthy housing, low income/benefit, food insecurity, unsafe relationships). 


\section{St Vincent de Paul, Wellington Area}

SVDP is a Catholic lay organisation committed to the concept of people helping people inspired by the gospel of Jesus Christ. Founded by Frederic Ozanam in 1833, it is an international organisation with branches operating in 142 countries. SVDP Wellington Area has established systems for providing practical assistance such as food parcels, as well as the facility to provide assistance with clothing, furniture and budgeting for those who are really struggling.

Aside from this facility SVDP Wellington employs a part-time social worker. This role was originally fairly basic as not all branches provide a social worker, nor aim to have one. However SVDP Wellington, like all SVDP branches, has a commitment to social justice and making a positive change in the community. Hence they responded to the high level of need seen in our community by hiring a social worker and pay all associated costs for it from the profits from the SVDP second-hand stores, donations and bequests.

\section{The beginning}

\section{Amy}

Upon being employed as the social worker for SVDP, there was a desire expressed by the agency for the social work role at SVDP to grow and develop. Naturally I was keen for this to happen but did not simply wish to duplicate existing services or create something that would not serve the needs of the community. Experience as a social worker within some diverse settings had taught me that for a role to genuinely grow in a responsive fashion rather than blindly expand, a real comprehension of the community is needed. The SVDP board were brave enough to let me analyse the role, take the temperature of the community and have the necessary time to develop it in response to the community needs regardless of whether those needs were accompanied by government or community funding. They continue to be pioneering today by allowing the parameters of my work to be shaped by the needs of our clients and have supported this article.

I was extremely fortunate in my journey to ascertain areas of need that there was a preexisting group providing peer support to social workers from the Newtown community already in place. Through this forum I was able to develop the relationship between SVDP and other community agencies, learn where the pressures on providers were and ensure my understanding of existing services was broadened. The key relationship from this network was with Stefanie from NUHS. NUHS is the primary health care provider for the vast majority of my clients and as the social worker there Stefanie had an incredible oversight of the community and its needs.

Collaborating and communicating daily with Stefanie as well as monthly with the peer support group, it soon struck me that while there was a wealth of experience, services and skills present in our community, services and therefore social workers were stretched. There were also gaps in service provision where some people could not access services due to not meeting criteria or having utilised their maximum support allocation. This alerted me to the reality that any development at SVDP, if it was to alter these circumstances, would have to be creative and not simply seek a funding contract from Government. To do so would almost certainly mean competing for funding with our sister Newtown organisations and either just rearranging or even potentially thinning out the service provision currently available to clients and further stressing agencies. 
Virtually all social service agencies in our community work within a highly contracted environment. Funding contracts are won and must be met or funding will be moved or lost. Social workers are employed to fulfil these contract obligations; some with high needs mental health consumers, some with the elderly, some with young people and so on. Specialisation is logical when one considers that areas of need often require specific skills and knowledge and a direct focus. Yet funding contracts can and do require more than specialisation to a particular target group. They frequently necessitate meeting government-defined 'outputs' meaning only so much time/resource can be spent on each client.

As I reviewed our communities' social services and their contracts I considered that the competitive nature of accessing increasingly limited funding contracts could contribute to the much maligned silo effect, where many agencies engage with one family and do not share information or get the complete picture. ${ }^{2}$ Each agency may engage with a given family to fulfil different contractual obligations and despite the best efforts of staff may not have known much about the other workers, may have perceived their work as distinct and therefore communication unnecessary, or even have viewed other agencies as competitors, not allies. Furthermore in this kind of scenario the information each agency has access to may have been quite limited as it is a shockingly large ask to expect one family to form a working alliance with many different workers. One or two is quite challenging enough.

Having considered these factors the difficulty I now faced was to develop SVDP strengths and strive towards improving our whole community response to vulnerability rather than simply aiming to compete, duplicate or reinvent.

\section{Stefanie}

From my theoretical understanding of social work and, therefore, as part of my social work practice, I have always seen it as of utmost importance in all of my positions that I cooperate and collaborate with social workers among other professions in the community. Building well-functioning networks has been of even more importance for me in the cases of being the sole social worker within a service. To sum up, I brought this kind of theoretical underpinning with me when I started my social work role at NUHS.

The social work role at NUHS, as with many other services in the community, is contracted to work with a specific group. This group is women and children. At the same time, NUHS experiences an array of issues on a daily basis which is characteristic of primary health care practices (Gross, Rabinowitz, Feldman, \& Boerma, 1996). In order to meet both realities, I decided to work from a generalist social work perspective within my contracted focus on women and children. The rationale behind this decision was that such an approach would: A) best meet the various needs of clients and B) offer an entry point for appropriate health social work support within the service as well as in the wider community.

In my experience there are downsides to this contracted focus and generalist approach. Firstly, people who do not fit the inclusion criteria are not able to access my support. Secondly, clients who have specific needs or needs which I cannot meet have to access (additionally) other services for support.

Indeed in 2012 media covered an incident of child abuse where there were 25 agencies involved (Fairfax Media, 2012). 
Consequently, people may fall through the gaps by not meeting the criteria. Alternatively, families may end up being linked with a huge number of different service providers or having to experience service providers who are not communicating and cooperating well with each other. Our communities cannot afford and should be not expected to engage in such ways. In order to prevent both mentioned issues as much as possible, it was clear to me that I would need to establish an extensive and well-functioning network with social workers and the varied services in the community.

\section{The growth}

\section{Amy}

To begin growing our service I undertook an audit of SVDP strengths, which, as expected, initially lay in the infrastructure that was set up to provide for practical needs such as food and clothing. Observation over some months also showed me that we were having contact via the provision of food with a range of clients, both those engaged with other services as well as those who were completely disengaged from any other service providers. For those who were disengaged two categories of disengagement were visible, the hardened and suspicious client with negative perceptions of social workers based on poor experiences and the client who just does not quite meet anyone's criteria for support.

For those who were engaged in other services I observed that many were having a need met (for example addiction treatment), yet were struggling with day-to-day management of their lives on a more basic level. For example they were struggling with housing, a loan shark or difficult family dynamics. The potential for long-term support from SVDP to sit alongside such treatment could potentially make a real difference to the client's ability to work well with their specialist service provider.

Regardless of where in this spectrum they fell, the basic human needs of Maslow's hierarchy (Maslow, 1954) were drawing these people in to SVDP. The potential for us to take our old service based upon charitable ideals, and use our strengths to move towards developing engagement on a deeper level with anyone and everyone who came in through our doors was undeniable. Discussing food, budgets, debt and daily routine could provide the unthreatening environment needed to uncover issues such as domestic violence, mental health struggles, trauma, grief and loneliness. Once these issues emerged the alliance built with SVDP could be utilised to plan towards the accessing of specialist services where needed.

Furthermore this was actually achievable with the right level of commitment and work for we were not bound by the parameters of an existing social work contract. Serious time could be invested into engaging clients and building relationships based on self-identified need. What was needed to action this aim was the three 'big c's' communication, collaboration and community buy in. With Stefanie's support I set about ensuring that these goals were met.

\section{Stefanie}

I quickly realised the diversity of (mental) health, social and other services in Newtown and the Wellington area. The beauty hereby has been that most services are in such close proximity. Hence, it was easy to explore the primary health care sector during my induction time. There was also a peer social work group set up within our Primary Health Organi- 
sation (PHO) as mentioned earlier by Amy. It was an easy welcome and quick way to get social workers to know each other. Furthermore, colleagues always had an idea who may be good to catch up with in the community.

In my meetings with social workers from other agencies, we would normally talk about our services, funding requirements, social work roles and boundaries. We would also verbally establish how we could work together for potential mutual clients. I have never had any written, formal memorandums of understanding. It was never needed so far as it has been working well (at least from my perspective).

Amy at St Vincent de Paul is one of the social workers with whom I have established successful cooperation. I contacted her the moment she started her work. The reason for this early contact was that one main concern for me was that many families I worked with struggled to meet their basic needs. Food security and with that often specialised budgeting and debt management were issues I was not able to address. Therefore, I needed the support of another social worker.

Our well-functioning cooperation has enabled clients and me to access Amy's social work support smoothly and flexibly. One exceptional benefit for me is our arrangement that I can arrange food parcels from her service on a one-off basis without a client needing to have an appointment with Amy and explaining everything again. This assistance has been very valuable to me because it is only available from SVDP and I can access it the same day, even if Amy should not be at her workplace. Clients have appreciated this support hugely as they are helped very smoothly in what can be described a crisis situation for them. Hence, I utilise it very purposefully and rarely, based on a careful social work assessment.

Another positive consequence from our well-functioning cooperation is that I have been able to direct my colleagues (such as social workers, community health workers, nurses, general practitioners, midwives) from NUHS and other health services in regard to clients who do not meet the criteria to receive my social work support for appropriate support to SVDP. The collaboration has been very well received by NUHS and led management to nominate our practice model for the CCDHB awards 2012.

\section{Today}

\section{Amy}

Today the renamed community social worker position deals with hundreds of clients from a broad range of ages, ethnicities and backgrounds. Having the door open to every person that wishes for support, and developing the trust of other agencies and community has seen a huge increase in numbers of clients accessing our service. It has also seen the successful engagement of clients with Women's Refuge, Newtown Union Health Service, Community Alcohol and Drug Services, Alcoholics Anonymous, PATHS and many more services. We are committed to tracking and responding to the evolving needs of our community, engaging people where they are at and communicating with other service providers. Perhaps most importantly, relationships can be built with many of the most vulnerable in our community with no set topics, exit dates or session limits other than those we agree on together.

I now have many clients who are fully engaged with other service providers but have contact with me to keep on track, get support and manage the day-to-day aspects of their 
lives. As local agencies have come to understand the benefits SVDP can offer, I receive referrals from agencies for their clients who are needing support with food or other practical needs who either cannot or will not engage in other service provision or who would benefit from a shared approach. For many services SVDP acts like a safety net, a client's need or vulnerability is identified, yet is outside the purview of their organisation and/or rejected by the client. Practical assistance from SVDP can be offered in these circumstances with the knowledge that we provide a level of safety for the client. For example I can engage with a person dropping in to get food to slowly build a relationship, trust and then a working alliance.

The greatest strength of this model is in the ability to keep the client at the centre. Many agencies face conflicting pressures from output expectations, session limits, performance requirements and so forth that make it more difficult to focus on the client and community needs. This can be seen visually below:

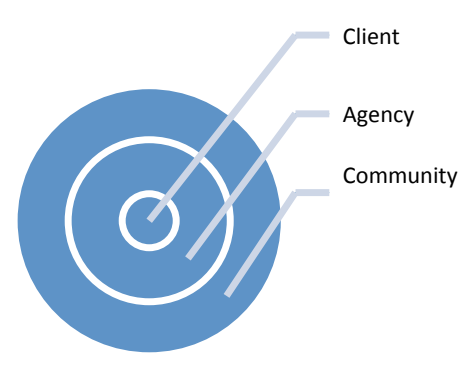

Community social worker role

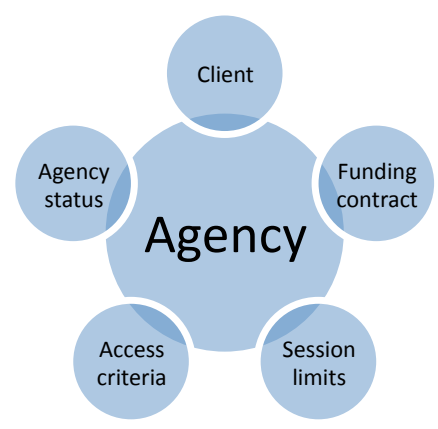

Pressures on contracted agency

\section{Stefanie}

Amy's social work role has evolved from offering food parcels, clothing / furniture, specialised budgeting and debt management over time. Her cross-sector social work experience has allowed her to analyse clients' situations in a much broader sense. Hence, her work enriches the benefit for three groups.

Firstly, the people who seek her support.

Secondly, Amy enhances the benefit for me and NUHS, especially in situations which involve child protection concerns, or in which clients and their families experience domestic violence. For example, she enables us to increase crucial support for clients and their children in very vulnerable situations and to mitigate stress factors. Furthermore, I can consult with her in such critical situations where the importance of team work is widely recognised (Lloyd, King, \& Chenoweth, 2002). I cherish these consultations in general but even more due to my position of sole social worker in my agency.

Thirdly, Amy's social work role is incredibly valuable for social workers (and others) because her role fills important gaps in the community. Social workers like me who are contracted to work with a specific group, who operate within (highly) financially regulated or specialised social work roles are restricted in their support. In comparison to us, Amy has 
been enabled to attract people from all walks of life who often come from most vulnerable situations. She can build relationships without needing to meet widely endorsed funding requirements as Amy described above.

\section{Future}

\section{Amy}

Now that SVDP has a strategy for engaging clients and meeting the needs of our community there are several points to consider. One is that when a service is successful in tapping into a need, it can soon be pushed beyond its capacity to cope with the increase in demand. This is certainly the case with SVDP. While we have proven the value of working outside of a specific funding contract in terms of gaining overwhelming positive community response and a significant increase in client numbers, this cannot be sustained in perpetuity without additional resource. Hence we need to work on identifying how the flexible community social work role can be resourced in the long term and even applied to other communities. Demonstrating through client and community evaluation that the role meets a need despite not having a select 'target audience' is crucial to achieving this.

For this model to work into the future it is also necessary for the model to become absorbed into the culture of both my own agency, NUHS and others within Wellington East so that it can outlast both of us as individual workers and be implemented successfully by the appropriate candidates who will replace us in the future. Moreover it is important that the model stands on its own and is not simply linked to us as people as it will allow continued growth and development.

\section{Stefanie}

The current environment of funding cuts and unhelpful policy modifications is negatively affecting the primary health care sector; for example, services are reduced or cut and positions are disestablished or restructured. Of specific concern are workload issues and competition of services for funding which may impact on the commitment and ability of services for collaboration. Therefore, I believe that an agency such as SVDP is in a unique position and absolutely needed to flexibly meet the needs in the community.

From my theoretical and practice standpoint, I will always be committed to work alongside other services within the community. The main reason for this approach is that I want to ensure that my clients (and NUHS patients) get the best and smoothest support in our community. Some collaboration will be closer and some looser, depending on the issues my clients and I experience. SVDP will be one of the services with which I will keep a close working relationship.

As pointed out by Amy earlier, ensuring a sustainable relationship is of importance if such an outlined practice model is to survive individual workers. In order to achieve sustainability, frontline social workers need to be expected (and supported by their organisations) to regularly attend local fora. The social work peer group of the PHO in Wellington is such an example. I would even go so far that there is a need for formal commitment to prioritise collaboration and communication between all main social services within a specific community. The rationale behind these suggestions is that this will help to identify any gaps and 
where the community social worker is most needed. This process will also benefit agencies to work together to provide strong, cohesive and relevant services to their community. It is anticipated that the frontline social workers as a group will build a powerful and unified basis to achieve sustainability of the practice model.

\section{Challenges and learnings}

\section{Amy}

The key challenges for this role are structural, in that they are generated by the complex and difficult political environment social service providers exist within. To provide the kind of service that is genuinely centred around the client, significant pushing back against obstacles that threaten this must occur and reoccur. For example, there is an ongoing challenge to communicate effectively with the community what it is that SVDP does and how it complements rather than undermines other services in existence. The cry can be heard from mental health/domestic violence/youth (fill your practice field here) fields that we are not a mental health/domestic violence/youth provider. This is true, nor do we aim to be and the challenge is to communicate that we are working to capture those who most likely would never reach their services, build their engagement with an experienced social worker at SVDP with the aim of future connection with a specialised service.

Conversely a challenge exists in ensuring that service providers do not begin to utilise the open door policy of SVDP to dump clients that are considered too risky, too complex or 'hopeless' on SVDP to improve their own 'outcomes' without actually providing for the client. To that end there is again a communication challenge requiring continual relationship building with service providers to ensure there is a shared understanding of SVDP service and objectives.

There is also a challenge presented to SVDP on how to measure and evaluate success in order to 'prove' its worth to any possible funders. This is a real juggling act between ensuring that measures provide good evidence, without closing doors for clients as this would be contrary to the objectives of the open role. For example, if exiting a client within a certain timeframe was utilised as a measure of success, this may preclude seeing as 'successfu' the client who still stops in once a month to 'stay on track' with her sobriety and new independent life. Likewise if simply being able to refer a client on was used as a measure of success, then this may impede our commitment to work alongside a client where needed as they engage with another provider. There are endless examples of how these kinds of measurements can compromise service, and yet measures are needed so the service can be evaluated by others and reflect upon itself. Building and maintaining a strong client feedback strategy, utilising qualitative research and a modern database system are options to meet this challenge.

\section{Stefanie}

Generally, I appreciate diversity within the primary health care sector as social worker because it offers something for (hopefully) everyone in the community and reflects creativity. At the same time, such variety can be negative if it means that 'the wheel is re-invented', services are duplicated over and over again, 'territorial' thinking occurs or there is confusion about who is providing what. Therefore, it is crucial that services 
are prepared to communicate and cooperate well. Successful communication and cooperation can lead to a potentially much needed social work service in a community such as SVDP in Wellington.

Funding problems and potential competition for funding is especially of current concern for me. Social workers and their services need to unite and face these difficult times together though I acknowledge potential restrictions of frontline social workers to do so (such as management directions or workload). Then, it is possible that a social work service like SVDP can be an example of how gaps in the community can be flexibly, quickly and successfully addressed. Nevertheless, I admit there are limitations to any kind of financial freedom when a growth like one described at SVDP occurs and that will be a challenge in itself.

\section{Conclusions and recommendations}

It is not a surprise to anyone working as a social worker that funding contracts are rarely adequate. Nor is it unanticipated that, despite a plethora of contracts existing, there are still people who fall through the cracks between contracts. These are issues that many social workers will have encountered at some point in their careers. The value in the practice model that we have developed is not in the identification of these challenges, but in the subverting of the response to them. Instead of joining the competition for funding, the model develops the ability of the independent community social worker to fill current service gaps as well as support other agencies.

Overall we recommend this model as one that could add value to any community. It is not, however, a model in the sense that it can be superimposed upon other areas in exactly the same way as it has developed for us. The most important factor in the success of this role is that it is led by clients and frontline practitioners within a community in a truly 'bottom up' approach, rather than the more standardised and 'top down' model. This will ensure that engagement from within your own area is strong and the role is allowed to grow and evolve in response to your own community's needs.

Despite the need for flexibility and local responsiveness there are some things we have learned from our journey that would be valuable in carrying a role such as the SVDP role across into any other community. Firstly we would strongly recommend that the social worker employed has several years of social work experience and in different fields especially knowledge of and skills in child protection as well as the mental health, addictions and domestic violence fields. This is to ensure the worker has the necessary skills to respond adequately to the myriad of presenting issues one sees in an open community-focused role.

Secondly, a social worker should have skills in research, developing services and dealing with management issues. This is because a vital part of the role of the community social worker will be to draw organisations together (sometimes against the agencies' previous inclinations), and to be part of building strong and efficient communication between sectors.

We also consider that the journey in collaborating around the SVDP role provides not only a practice model to consider but some wider discussion points for the social work community. For example, while we may be constrained to a degree by the political environment which contributes to funding and policy decision making, at what point do we have 
a responsibility to be creative and challenging in our response to this? What are the options for agencies working together and supporting one another for the benefit of the client and community and who want to move from operating in the 'silos' that have been so discussed and maligned? We are proud of our community social work model and hope to be part of more discussion and thinking in this area.

\section{References}

Aimers, J., \& Walker, P. (2008). Is community accountability being overlooked as a result of government-third sector partnering in New Zealand? Aotearoa New Zealand Social Work Journal, 20(3), 14-25.

Carey, M. (2008). Everything must go? The privatisation of state social work. British Journal of Social Work, 38(5), 918-935.

Fairfax Media. (2012). Bennett: Adult after adult let tortured girl down. Retrieved from TVNZ website: http: / / tvnz. co.nz / national-news / three-year-sentence-father-abused-girl-4713012.

Ferguson, I. (2008). Reclaiming social work: Challenging neo-liberalism and promoting social justice. London: Sage.

Gross, R., Rabinowitz, J., Feldman, D., \& Boerma, W. (1996). Primary health care physicians' treatment of psychosocial problems: Implications for social work. Health and Social Work, 21(2), 89-95.

Harms, L., \& Connolly, M. (2009). The art and science of social work. In L. Harms \& M. Connolly (Eds.), Social work: Contexts and practice (Vol. 2). Melbourne: Oxford University Press.

Hibbs, S. (2005). The state, professionalisation and social work. Social Work Review, 17(2), 38-42.

Hughes, M., \& Wearing, M. (2007). Organisations and management in social work. London: Sage.

Lloyd, C., King, R., \& Chenoweth, L. (2002). Social work, stress and burnout: A review. Journal of Mental Health, 11(3), 255-265.

Maslow, A. H. (1954). Motivation and personality. New York: Harper.

Newtown Union Health Service. (2011). Annual Report.

Statistics New Zealand. (2006). Quick stats about Newtown East. Wellington: Statistics New Zealand. 